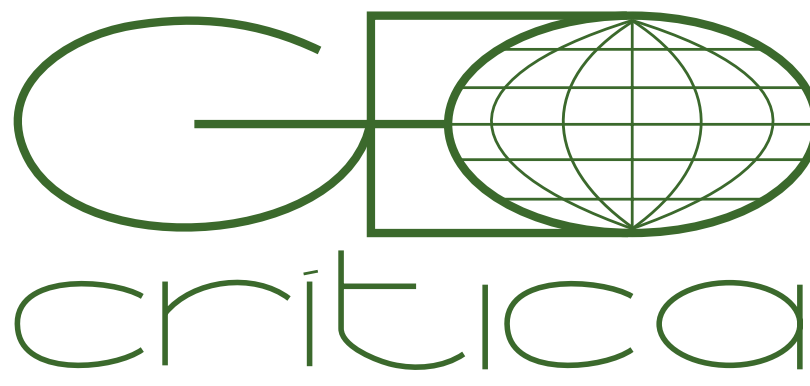

Revista Electrónica de Geografía y Ciencias Sociales Universitat de Barcelona

\title{
RELACIONES INTERÉTNICAS Y LUCHA CONTRA LA GENTRIFICACIÓN EN EL BARRIO DE EL ABASTO (BUENOS AIRES)
}

\author{
Francisco José Cuberos Gallardo \\ Centro de Investigação e Estudos de Sociologia - Instituto Universitário de Lisboa (CIES-IUL) \\ francisco.jose.cuberos@iscte-iul.pt
}

Recibido 28/9/2017. Devuelto para correcciones: 28/1/2018. Aceptado 5/3/2018

Este trabajo se enmarca en el proyecto de investigación "Imigração e conflito urbano: o direito à cidade diversa em Latino-América e na Península Ibérica", financiado con una beca postdoctoral por el Ministério da Ciência, Tecnologia e Ensino Superior de Portugal (Fundação para a Ciência e a Tecnologia). El trabajo de campo contó con el apoyo financiero del proyecto "Multilevel governance of cultural diversity in a comparative perspective: EU-Latin America", financiado por la Comisión Europea a través del programa IRSES-Marie Curie.

\section{Relaciones interétnicas y lucha contra la gentrificación en el barrio de El Abasto, Buenos Aires (Resumen)}

El barrio de El Abasto (Buenos Aires) ha experimentado una notable transformación urbanística durante las últimas dos décadas, derivada de la inversión en el área de una gran cantidad de capital financiero. Esto se ha traducido en una fuerte presión gentrificadora, que amenaza especialmente a los sectores más vulnerables del vecindario. En este artículo se apuesta por el método etnográfico para explorar el efecto diferenciado que este fenómeno ha tenido sobre la población inmigrante del barrio, mayoritariamente de origen peruano. Más allá de la dimensión puramente monetaria, la intervención gentrificadora ha exigido en El Abasto una inversión simbólica en la construcción de un discurso patrimonialista, que presenta a la población inmigrante como usurpadora del espacio. Los datos recabados evidencian que ello se traduce en una mayor exposición de la población inmigrante al problema, y en una tendencia por su parte a desarrollar formas diferenciadas de resistencia a la gentrificación.

Palabras clave: Gentrificación, relaciones interétnicas, Inmigración, Peruanos, Buenos Aires.

\section{Ethnic relations and fight against gentrification in El Abasto, Buenos Aires (Abstract)}

The neighborhood of El Abasto (Buenos Aires) has undergone a remarkable urban transformation during the last two decades, derived from the investment in the area of a large amount of financial capital. This has resulted in strong gentrification pressure, which particularly threatens the most vulnerable sectors of the neighborhood. In this article, the ethnographic method is used to explore the differential effect that this phenomenon has had on the immigrant population of the neighborhood, mostly of Peruvian origin. Beyond the purely monetary dimension, gentrifying intervention has demanded in El Abasto a symbolic investment in the construction of a patrimonialist discourse, which presents the immigrant population as a usurper of space. The data obtained show that this translates into a greater exposure of the immigrant population to the problem, and a tendency on its part to develop differentiated forms of resistance to gentrification.

Keywords: Gentrification, Interethnic Relations, Immigration, Peruvian, Buenos Aires 
Ubicado en el corazón de la ciudad de Buenos Aires, el barrio del Abasto alberga en la actualidad una de las principales comunidades de inmigrantes peruanos en la capital argentina. Esta población ha sufrido, como el resto de vecinos de la zona, los efectos de una profunda transformación urbanística derivada de la inversión de una cantidad ingente de capital financiero, y orientada a la obtención de plusvalías a través de mecanismos especulativos. El proceso de gentrificación del Abasto se ha traducido fundamentalmente en un fuerte ascenso del precio del suelo, pero también en la llegada a la zona de nuevos actores, nuevos usos para sus espacios públicos, nuevos discursos sobre el barrio y sus habitantes y una creciente presencia de dispositivos de vigilancia. Todos estos cambios han tenido un impacto decisivo en la vida cotidiana del conjunto de los vecinos, y han propiciado la emergencia de formas organizadas de resistencia a la presión gentrificadora.

En este artículo nos proponemos una descripción crítica de la evolución urbanística del Abasto a lo largo de las últimas dos décadas, así como un análisis de su impacto en las relaciones interétnicas que atraviesan el barrio. Para ello tomamos como referencia el caso representado por un conjunto de veintisiete familias, residentes en la zona y afectadas por una situación dramática que les obliga a acelerar un proceso de auto-organización y movilización activa para poder seguir viviendo en el Abasto. El 21 de julio de 2016, una vela prendida por una niña tras varios días de cortes de luz desata un incendio que afecta a la totalidad de una vivienda ubicada en la calle Zelaya, a apenas doscientos metros del monumental Shopping Abasto que ha devenido en centro neurálgico de la vida del barrio e imagen física del nuevo Abasto. El edificio afectado, distribuido según el modelo típicamente conocido como casa-chorizo ${ }^{1}$, alberga a un total de veinticuatro familias peruanas y tres argentinas, todas de condición humilde y alojadas de manera irregular. La gravedad del accidente, que provoca la pérdida de todas las pertenencias de muchas de estas personas, les lleva a improvisar un campamento frente al edificio en el que pasarán los dos meses siguientes, reivindicando su derecho a continuar viviendo en el barrio. Será en el marco de esta acampada que los vecinos comiencen a desarrollar un amplio abanico de iniciativas para mitigar su situación y exigir una solución definitiva. Y será también aquí donde estas personas converjan en sus movilizaciones con otros actores del barrio, incluyendo partidos de izquierdas, movimientos sociales, asociaciones de inmigrantes, comerciantes y vecinos a título particular.

La experiencia desarrollada por estas familias ofrece un rico material para la reflexión sobre algunos de los principales debates que hoy atraviesan los estudios urbanos, y muy particularmente sobre la complejidad de impactos y respuestas observables en torno a los procesos de gentrificación. Más allá de la lógica unívoca que estos procesos presentan en su dimensión económica, proponemos un acer-

1 Este modelo de vivienda, común en las ciudades de Buenos Aires y Rosario, se dispone como un conjunto de habitaciones orientadas en hilera a lo largo de un patio lateral. La denominación chorizo alude al hecho de que estas habitaciones suelen estar unidas entre sí a través de puertas. No obstante, en casos como el que ilustra nuestro estudio, cada habitación es ocupada por una familia, y no suele hacerse uso de las puertas interiores. 
camiento crítico que recoja la pluralidad de sus efectos sobre poblaciones diversas. Nuestra hipótesis es que las poblaciones migrantes experimentan la gentrificación de un modo diferenciado, tanto por las formas y la intensidad con que sufren sus consecuencias como por las estrategias que desarrollan para enfrentarla. Para contrastar esta posibilidad teórica aportamos datos recabados a partir de un trabajo de campo de corte etnográfico, basado en la implementación de técnicas propias de la Antropología urbana. Así, el trabajo que se presenta se basa fundamentalmente en una labor intensiva de observación participante, a partir de una inmersión directa del investigador en la vida de las familias afectadas por el incendio de la calle Zelaya, y que incluye la participación constante y sistemática tanto en sus iniciativas más formalizadas como en el transcurso de sus relaciones cotidianas. Igualmente se desarrolló un seguimiento permanente de la actividad de otros sectores involucrados en el problema, incluyendo organizaciones políticas -Nuevo Encuentro², Patria Grande3, La Brecha4-, movimientos en defensa de la vivienda -Coordinadora de Inquilinos de Buenos Aires (CIBA) 5 - y asociaciones de inmigrantes -Asociación de Mujeres Unidas, Migrantes y Refugiadas en Argentina (AMUMRA) ${ }^{6}-$, así como líderes informales de la comunidad peruana en el barrio y representantes del comercio de la zona. La aplicación de entrevistas en profundidad permitió recoger los discursos de todos estos actores, a través de un guión en el que se abordaban tanto las transformaciones urbanísticas acontecidas en el barrio como las relaciones interétnicas que articulan la vida social del mismo, así como cuestiones relativas a la actualidad política y económica del país. Finalmente, la recolección de los datos fue completada a través de una intensa labor de análisis documental, que incluyó el repaso sistemático de los discursos sobre el barrio que continuamente aparecen en medios de comunicación escritos y audiovisuales, pero también la consulta de bibliografía específica sobre la historia del Abasto y sobre los planes urbanísticos aplicados en tiempos recientes.

A continuación presentamos algunos de los conceptos teóricos de referencia para nuestro estudio, enmarcándolos en los debates académicos en que se inscriben y que les dan sentido. A partir de estos debates, y a modo de contexto, se ofrece un

2 Nuevo Encuentro es un partido político de centro-izquierda, nacida en el año 2009 en torno al liderazgo personal de Martín Sabbatella, y que ha evolucionado hasta integrarse de facto en el amplio espectro del kirchnerismo.

3 Patria Grande es un partido político nacido en 2014 a partir de la fusión de varias organizaciones de izquierda, que se construye igualmente desde una óptica de apoyo crítico al kirchnerismo y con énfasis en el objetivo de la integración regional latinoamericana. 4 La Brecha es una coordinadora de organizaciones de base cuyo objetivo es construir poder popular, fundamentalmente mediante el trabajo en los barrios, desde una perspectiva anticapitalista, antipatriarcal y antiimperialista.

5 La CIBA es un movimiento autónomo que lucha desde los años 70 por el derecho a la vivienda en la capital argentina, concentrando sus reivindicaciones en la suspensión de los desalojos, la regularización del mercado de alquileres y la construcción de vivienda social.

6 AMUMRA se define como una organización civil de Derechos Humanos que trabaja por la calidad de vida de las mujeres migrantes y refugiadas. Funciona desde 2001 e integra mayoritariamente a mujeres peruanas. 
repaso somero a la evolución histórica del barrio del Abasto, deteniéndonos especialmente en los cambios acaecidos durante los últimos veinte años. Posteriormente, nos adentramos en la descripción etnográfica de nuestro caso de estudio, que es organizada en dos partes. En la primera reflexionamos sobre la situación de las familias estudiadas, deteniéndonos en sus discursos sobre el barrio, sus relaciones con los vecinos y sus percepciones sobre las transformaciones recientes. En la segunda analizamos de manera específica las estrategias desarrolladas por las familias peruanas para evitar su expulsión del Abasto, atendiendo tanto a la singularidad de sus prácticas y discursos como a sus pautas de interacción con otros sectores. Finalmente, incluimos un breve apartado en el que recogemos las principales ideas derivadas de nuestro trabajo y contrastamos su aportación potencial a los debates sobre las transformaciones urbanísticas y sus efectos sobre las poblaciones migrantes.

\section{Economía, poder y cultura en los procesos de gentrificación}

En términos genéricos, la gentrificación puede ser entendida como "un proceso que implica un cambio en la población de usuarios del suelo de tal manera que los nuevos usuarios son de un nivel socioeconómico más alto que los anteriores usuarios, junto con un cambio asociado en el entorno construido a través de una reinversión en capital fijo" ${ }^{\prime \prime}$. Este fenómeno urbanístico, detectado por primera vez en los centros urbanos de grandes ciudades anglosajonas, ha llegado a extenderse a nivel planetario durante las últimas dos décadas. A lo largo y ancho del mundo los procesos de gentrificación reflejan la penetración creciente de la lógica del mercado en el campo de la planificación urbanística. ${ }^{89}$ Cabe asumir con Casgrain y Janoschka que hay gentrificación cuando concurren cuatro condiciones: "1. la reinversión de capital en un espacio definido y un alza correspondiente del valor del suelo de ese espacio o en áreas colindantes; 2 . la llegada de agentes con mayor capacidad de pago que los usuarios establecidos en ese espacio o en áreas colindantes; 3 . cambios en las actividades y en el paisaje urbano controlados por los grupos que ingresan al territorio en cuestión; 4. el desplazamiento directo, o la presión indirecta para el desplazamiento, de grupos sociales de ingresos más bajos de los que entran".10

En la medida en que las minorías migrantes se insertan mayoritariamente en los estratos más precarizados de las sociedades urbanas, no es extraño que estos colectivos se cuenten con frecuencia entre los principales perjudicados por unas estrategias gentrificadoras que obedecen a los intereses del capital inmobiliario, y que cuentan frecuentemente con el respaldo político de los órganos de gobierno ${ }^{11}$. Hace ya veinte años Horacio Capel ${ }^{12}$ alertaba de que los inmigrantes se verían crecientemente afectados en el futuro por este tipo de planes de renovación urbana. Hoy

7 Clark, 2005, p.263

8 Aricó, Mansilla y Stanchieri, 2016

9 Weber, 2002

10 Casgrain y Janoschka, 2013, p. 24

11 Martínez Veiga, 1999.

121997 
podemos constatar que, en efecto, la necesidad ingente de rentas inmobiliarias por parte del capital financiero lleva a sus propietarios a fijarse cada vez más en espacios residenciales degradados y preferentemente centrales. Y es precisamente en estos barrios donde los inmigrantes suelen asentarse, en la búsqueda de precios asequibles para el alquiler o la compra y de buenas condiciones de acceso a los espacios de trabajo en que mayoritariamente se insertan.

La gentrificación por tanto es parte indisociable de las nuevas geografías urbanas que emergen "como horrorosa imagen especular de la absorción de capital excedente mediante el desarrollo urbano". ${ }^{13}$ Es la expresión de los intereses de una clase, que confronta inevitablemente con los intereses antagónicos de otras clases, y que entraña un ejercicio de violencia pero también la generación de una reacción. ${ }^{14} \mathrm{Si}$ a la ciudad concebida por el capital se le opone siempre la apropiación de la ciudad vivida que ejecutan cotidianamente los sectores populares, ${ }^{15}$ cuando la concepción de la ciudad capitalista entraña un ejercicio extra de violencia, en forma de expulsión física y simbólica de lugares sentidos como propios, no es de extrañar que la oposición de los afectados adopte formas explícitas y organizadas. Los espacios inmersos en procesos de gentrificación nos ofrecen, en este sentido, laboratorios vivos para una exploración privilegiada de las formas espaciales del proyecto societal hegemónico, pero también de las estrategias de resistencia de los grupos que enfrentan dicho proyecto.

Para conservar y reproducir su hegemonía, el modelo socioespacial que inversores y especuladores impulsan a través de la gentrificación precisa movilizar, en paralelo al capital financiero invertido, una gama amplia de capitales culturales, relacionales y simbólicos ${ }^{16}$. En la medida en que dicho modelo confronta la ordenación previa del espacio y la somete a un reordenamiento violento, se hace necesario para sus defensores acompañar la apuesta económica de todo un conjunto de intervenciones de refuerzo en el plano de los discursos y de las relaciones que funcionan en el barrio. El éxito de este tipo de operaciones depende en gran medida de su capacidad para conectar en el plano simbólico con valores que sean respetables para la mayoría social, y que al mismo tiempo deslegitimen las estrategias de los sectores que se le oponen. Dotar a la intervención urbanística de legitimidad social constituye así un objetivo prioritario que absorbe buena parte de la energía de sus beneficiarios y que involucra con frecuencia a una multiplicidad de actores.

La gentrificación exige necesariamente la destrucción previa de vínculos sociales y formas de ocupación del espacio que preexisten en el tiempo y que contravienen la lógica de esta intervención urbanística. ${ }^{17}$ Ello explica que, en el marco de este tipo de operaciones, se observe una tendencia sistemática a la visibilización y estigmatización de colectivos y prácticas que son presentados como "problemáticos". El

13 Harvey 2013, p. 39

14 Winchester, Kong and Dunn, 2003

15 Lefebvre, 2013, p. 210

16 Casgrain y Janoschka, 2013

17 Dalmau i Torvà, 2016 
trabajo de Espinosa Zepeda ${ }^{18}$ sobre la desarticulación de los mercados ambulantes en zonas gentrificadas de Guadalajara (México) aporta una interesante descripción sobre cómo los vendedores ambulantes son redefinidos como sujetos física y moralmente "sucios" para legitimar su expulsión de la zona. También en el Abasto encontramos una tendencia evidente a caracterizar a los inmigrantes en estos términos: como personas sucias y mal educadas que empobrecen el ambiente urbano y que representan en suma un obstáculo al progreso de la ciudad.

Otro rasgo recurrente en estos ejercicios de estigmatización de los sectores populares contrarios a la gentrificación es presentarlos como usurpadores del espacio. El objetivo en este caso es justificar la intervención urbanística como una restitución del orden legítimo de las cosas, que habría sido previamente violentado por dichas poblaciones. Para ello se construyen narrativas que conectan ciertos lugares en un relato genealógico que dota al barrio de una historia aparentemente armónica y lineal, y cuya continuidad exigiría la implementación de la intervención urbanística y la expulsión de los grupos que violentan esa tradición. Son estas formas de "tematización" de la identidad del barrio las que permiten presentar a los inmigrantes como usurpadores del espacio -físico y simbólico- ${ }^{19}$ y las que motivan con frecuencia que la intervención gentrificadora sea acompañada de un proceso de activación patrimonialista.

Tal y como Harvey ${ }^{20}$ ha argumentado de manera convincente, la reivindicación del valor patrimonial de un barrio ofrece una ventaja intrínseca a la inversión inmobiliaria, pues refuerza por sí misma la imagen de unicidad, autenticidad, particularidad y especificidad que otorga valor al producto. Pero además, y paralelamente, esta valorización del patrimonio histórico-cultural del barrio puede ser usada como un arma contra los opositores a la gentrificación, si se consigue presentar a éstos como actores externos al barrio y peligros potenciales para la conservación y el aprovechamiento de su patrimonio. Tratando con el propio caso del Abasto, Carman ha explicado cómo en la medida en que se activan los discursos patrimonialistas, los ocupantes de viviendas pasan a ser vistos como triplemente usurpadores: usurpadores por el valor material de las casas, usurpadores del territorio nacional -por ser vistos generalmente como extranjeros e indocumentados- y usurpadores del valor patrimonial del entorno. ${ }^{21}$ El proyecto de gentrificación del barrio no descansa exclusivamente sobre la inversión de capital financiero: reclama paralelamente una intervención profunda a nivel cultural, orientada a deslegitimar el régimen socioespacial preexistente y justificar así la necesidad de una intervención violenta.

Ahora bien, en estas condiciones ¿qué respuesta cabe esperar de las poblaciones afectadas?

Frente a la presión especulativa que pugna por expulsarles de su barrio para hacer de éste un objeto de negocio, los vecinos se ven impelidos a construir formas

182016

19 Kong and Yeoh, 2003

202013

21 Carman, 2006, p. 160 
de reciprocidad y apoyo mutuo como modo de reforzar estrategias de resistencia. La prestación de formas variadas de ayuda entre vecinos se convierte en este contexto en condición necesaria para paliar las necesidades particulares de cada uno de ellos, pero también para reforzar la posición colectiva y para respaldar sus intereses en valores alternativos. Ciertamente, la penetración de la vida social por el individualismo y la competencia que rigen la lógica neoliberal ha restringido notablemente las condiciones de posibilidad de formas amplias y duraderas de solidaridad en los barrios. Sin embargo, y como afirma Harvey, la "conducta vecinal" asociada a este tipo de prácticas resurge de manera reforzada en el seno de comunidades amenazadas. ${ }^{22}$ La propia amenaza gentrificadora puede actuar como un acicate de dicha conducta. La existencia de un espacio en disputa tiene a menudo el efecto de fomentar la solidaridad y la confianza mutua entre quienes reivindican su control frente a otros grupos. ${ }^{23}$

En el caso de las poblaciones migrantes, este efecto se manifiesta básicamente en dos tendencias. Hacia el interior del grupo, la necesidad de crear y sostener en el tiempo redes de apoyo amplias y densas motiva un refuerzo de los referentes identitarios que pueden sustentarlas. La existencia de una identidad compartida, construida en términos étnicos, se torna un potente recurso desde el que movilizar recursos en beneficio de individuos particulares y de la comunidad en su conjunto. Diferentes autores han subrayado insistentemente cómo las comunidades que definen sus nexos en términos étnicos presentan con frecuencia una excepción al retroceso generalizado de las formas de solidaridad organizada en el medio urbano. ${ }^{2425}$ En este sentido, es frecuente que la identidad étnica o nacional compartida sea activada como un factor de cohesión desde el que reforzar las estrategias de resistencia a la expulsión del barrio.

Paralelamente, sin embargo, el hecho de verse afectados por una amenaza que afecta igualmente a otros sectores del barrio -autóctonos e inmigrantes de otras nacionalidades-, facilita la convergencia junto a esos otros grupos en el desarrollo de estrategias conjuntas. Esta tendencia ya fue observada por Glazer y Moyniham ${ }^{26}$ en su célebre estudio sobre la convivencia entre diversos grupos étnicos en la ciudad de Nueva York, cuando detectaron formas estables de cooperación entre negros y puertorriqueños contra la presión gentrificadora. La necesidad de enfrentar juntos un problema común favorece la aparición de iniciativas coordinadas entre grupos que, teniendo adscripciones étnicas diferentes, demuestran ser capaces de colaborar sin desdibujar por ello sus identidades diferenciales. Cabe esperar por tanto, en situaciones como la que atraviesa el Abasto, procesos de articulación organizativa entre grupos diferentes, que alumbran la conexión novedosa de redes, identidades y culturas políticas forjados en contextos muy distintos. Unos procesos que no están

22 Harvey, 1977, p. 295

23 Arenales, 2016, p. 130

24 Harvey, 2014, p. 189

25 Castells, 2003

26 1963, p. 300 
exentos de tensiones, y que exigen la puesta en marcha de mecanismos de negociación complejos tanto entre los distintos grupos como hacia el interior de cada uno. Para ilustrar la complejidad que estos procesos asumen en el Abasto y evaluar sus potencialidades y sus límites, es preciso comenzar describiendo la evolución histórica experimentada por este sector de la capital argentina.

\section{Origen y evolución del barrio del Abasto}

Si bien el Abasto es perfectamente reconocido por todos los habitantes de Buenos Aires, tanto el nombre de este barrio como sus límites carecen de reconocimiento administrativo. En términos oficiales, la zona se encuadra dividida entre los distritos de Almagro y Balvanera. Su extensión aproximada es de un kilómetro cuadrado, que engloba un total de sesenta cuadras limitadas por las calles Ecuador, Córdoba, Mario Bravo y Presidente Perón. En el centro del damero se encuentra el Shopping Abasto, un edificio colosalista de estilo art decó, cuya construcción en 1893 marca históricamente el origen del propio vecindario. Erigido como mercado central de frutas y verduras, la actividad comercial de este centro será la base que vaya aglutinando a un vecindario de ascendencias muy diversas. El censo de 1887 clasifica a la población de la zona como compuesta básicamente por italianos (46,95\%), argentinos $(35,65 \%)$, franceses $(7,25 \%)$ y españoles $(6,16 \%)$, sumándose poco después contingentes significativos de judíos, árabes, armenios, sirios, turcos y griegos ${ }^{27}$. La incorporación de estas poblaciones al área tiene lugar a través del modelo habitacional conocido como "conventillo", consistente en casas de varias habitaciones donde familias de escasos recursos conviven compartiendo estancias comunes como el comedor y el aseo. Un tipo de vivienda de gran importancia histórica en Argentina, pero también en Chile, Bolivia y Uruguay, y que se corresponde en términos generales con el que es conocido en España como "corral de vecinos".

La vitalidad comercial del mercado favorece que pronto proliferen en su entorno teatros, cantinas y prostíbulos, consolidándose a comienzos del siglo XX un singular ambiente que explica la conexión indisoluble del Abasto con la historia del tango. Más allá de que el mítico Carlos Gardel se criase en el barrio y comenzase en él su trayectoria artística, muchos otros artistas frecuentarán las cantinas del Abasto, incluyendo figuras de referencia como Aníbal Troilo, Astor Piazzolla o Roberto Goyeneche. Durante varias décadas, el barrio mantiene una intensa vida cultural, marcada por un halo de bohemia que lo liga a la vida nocturna, el consumo de alcohol, la presencia de prostitutas y la incidencia de riñas callejeras. Así, desde su fundación y hasta la década de los setenta, el Abasto irá consolidando una imagen ambigua, donde el resplandor artístico de los grandes tangueros se difumina en un ambiente turbio asociado al vicio, la violencia y la inseguridad.

En 1984 el mercado es clausurado y trasladado a la periferia ${ }^{28}$. Esta circunstancia se traduce pronto en un fuerte aumento del desempleo en la zona y, en general, en

27 Carman, 2006

28 Carman, 2006 
una degradación del ambiente urbano. Además, el cierre del mercado se da en paralelo a la aparición en Argentina de las ocupaciones ilegales de viviendas, fenómeno espoleado tanto por la situación económica del momento como por la rebaja de la represión violenta tras el fin de la dictadura militar ${ }^{29}$. A lo largo de los años ochenta buena parte de las viviendas del barrio van a ser ocupadas de manera irregular. Las "casas tomadas" pasan a representar una parte considerable del paisaje del barrio, y contribuyen a acentuar la preocupación por un área de la ciudad que alberga problemas de abandono, pobreza e inseguridad. Esta paulatina degradación del Abasto coincide en el tiempo con el arranque de la tercera gran corriente migratoria de peruanos a Argentina. Una corriente que, a diferencia de las llegadas hasta los años cincuenta primero y hasta los setenta después, presenta una mayor representación de clase media y media-baja, y se inserta en su inmensa mayoría en sectores laborales precarizados, destacando la construcción, el servicio doméstico y las actividades industriales ${ }^{30}$. En este sentido, la diferencia étnica que encarnan estos nuevos vecinos inmigrantes va a añadir un componente de diversidad al barrio, que según Heuse $^{31}$ será percibida como problemática por una sociedad cuya imagen de sí misma se construye en gran medida en torno al valor de la homogeneidad sociocultural.

A inicios de la década de los noventa la presencia de peruanos en territorio argentino comienza a experimentar un crecimiento sin precedentes. Entre 1991 y 2001, el número de peruanos residentes en el país pasa de 15.939 a 88.260, alcanzando en el año 2010 a un total de 157.514 personas ${ }^{32}$. Este fenómeno debe ser enmarcado en un contexto condicionado tanto por la crisis política y económica derivada de la llegada al poder de Fujimori en Perú como por la necesidad existente en Argentina de mano de obra barata en sectores laborales como el comercio, la industria y el servicio doméstico. Grandes contingentes de peruanos, pero también paraguayos y bolivianos, llegan a Argentina atraídos por la posibilidad de cobrar salarios en dólares merced al nuevo régimen de convertibilidad argentino ${ }^{33}$. Finalmente, conviene tener en cuenta que la llegada al poder de Néstor Kirchner en 2003 da lugar a una serie de transformaciones importantes en política migratoria, que se traducen en una mejora ostensible de las condiciones de entrada y residencia en el país para la población extranjera. En el mismo año 2003 es aprobada una nueva Ley de Migraciones que ensancha considerablemente los derechos de los no-nacionales, y muy especialmente los de los nacionales de otros países miembros del MERCOSUR. En ella se establece que los inmigrantes nacionales de dichos países podrán acceder a la nacionalidad argentina simplemente acreditando la suya de origen y la carencia de antecedentes penales. Igualmente, la Ley de Migraciones de 2003 reconoce el acceso irrestricto de todos los inmigrantes a la asistencia sanitaria pública y gratuita, independiente de su situación administrativa en el país. El 17 de abril de 2006, y como

29 Carman, 2005

30 Canevaro, 2008

31 Heuse, 2004

32 Cerrutti, 2012, p. 5

33 Cerrutti, 2005 
proyección política de la nueva ley, se da el pistoletazo de salida al Plan Patria Grande, orientado a regularizar la situación migratoria de los inmigrantes procedentes de países del MERCOSUR que se encontraban ya residiendo en Argentina ${ }^{34}$. Cuatro años más tarde, los datos oficiales del propio programa cifran en 423.697 el total de personas inscritas en el proceso de regularización, incluyendo a un total de 47.455 peruanos ${ }^{35}$.

Los inmigrantes peruanos van a radicarse de manera preferente en las grandes urbes argentinas, y muy especialmente en Buenos Aires. A diferencia de paraguayos y bolivianos, más concentrados en las zonas periféricas de la capital, la población peruana va a mostrar una predilección sistemática por ocupar las áreas centrales, valorando sobre todo su mejor dotación de recursos y la accesibilidad que brindan a los nichos de empleo. Autores como Cerrutti ${ }^{36}$ explican esta singularidad por ser la peruana una corriente migratoria más reciente, por estar conformada en su mayor parte por personas de extracción urbana y, por contraste con las otras dos corrientes citadas, por carecer aún de unas redes amplias y consolidadas que puedan compensar las desventajas de vivir en la periferia. En todo caso, el Abasto representa un caso arquetípico de espacio residencial predilecto para los peruanos, y concentra en su seno a una representación importante de esta población. Ellos representan a la mayoría de los aproximadamente mil inmigrantes que habitan el barrio, sobre una población total estimada en torno a las tres mil quinientas personas. Al igual que los vecinos llegados desde otras zonas de Buenos Aires o desde el interior de Argentina, la población peruana que llega al Abasto se acomoda mayoritariamente en los citados conventillos, concentrándose desde el principio en las zonas aledañas al antiguo mercado.

A fines de los noventa se da inicio a un conjunto de transformaciones urbanísticas que van a modificar definitivamente la realidad del barrio. En 1998 el edificio del antiguo mercado es reabierto al público, ahora como un centro comercial lleno de tiendas de moda, cafeterías, restaurantes y salas de cine. La operación se encuentra sufragada por Inversiones y Representaciones S.A. (IRSA), una empresa inmobiliaria argentina que desde comienzos de los noventa experimenta un crecimiento meteórico merced a la entrada de grandes inversionistas extranjeros, entre los que destaca el célebre magnate húngaro-estadounidense George Soros. La apertura del Shopping Abasto forma parte de un proyecto más ambicioso, que involucra una inversión total de unos doscientos millones de dólares en el Abasto y que pronto se completa con la construcción de tres rascacielos de viviendas de lujo -las célebres "torres-country"-, el hotel internacional Holiday Inn y un hipermercado ubicado en una parcela contigua al centro comercial. Paralelamente, la propia IRSA desarrolla una política de compra conjunta de dos manzanas completas de viviendas, así como de cinco esquinas estratégicas en los mismos alrededores del centro comercial ${ }^{37}$, con

34 Canevaro, 2008

35 Dirección Nacional de Migraciones, 2010

362005

37 Carman, 2005 
el fin de controlar estos espacios y arrendarlos para sectores sociales y actividades coherentes con sus objetivos en el barrio. Así, y partir de una reconfiguración del orden barrial que toma al Shopping Abasto como referente central, se emprende una intervención profunda que comienza por las cuadras aledañas, en las que pronto proliferan restaurantes temáticos, teatros, casas de antigüedades y tiendas de souvenirs ${ }^{38}$. Estos cambios alcanzan también a la disposición de los espacios públicos: la cortada Carlos Gardel, ubicada frente a la entrada del Shopping, es transformada en el año 2000 en una calle peatonal con buen adosado, farolas decorativas y comercios elegantes, y es coronada con la erección de una estatua en homenaje al propio Gardel, "Morocho del Abasto". La transformación urbanística de la zona apunta a un aprovechamiento material de su valor financiero, pero también a una reestructuración moral del barrio, que reivindica el valor de un patrimonio supuestamente en peligro y que presenta a los propios gentrificadores como garantes de su protección. Tal y como observa Díaz ${ }^{39}$ en su acercamiento al caso, la misma presencia de Soros en este proyecto será visibilizada como la de un mecenas preocupado por el patrimonio de todos los argentinos.

De hecho, la figura de Gardel va a ser explotada de manera intensiva a través de un proceso de activación patrimonialista claramente conectado con el propio objetivo gentrificador ${ }^{40}$. A pocos metros de la cortada Carlos Gardel, la casa donde nació el artista es reconvertida en un museo temático. El Zorzal Criollo va a hacerse omnipresente, apareciendo su rostro en chapas, imanes, camisetas y vidrieras de restaurantes, y cediendo su nombre a comercios, calles, plazas y hasta a la estación de metro de la zona. Por extensión, otras figuras del tango van a ser recuperadas para decoro del barrio, y van a ser homenajeadas con sus respectivas estatuas, rótulos publicitarios y placas conmemorativas. La herencia bohemia, tanguera y popular es así recuperada en paralelo a un embate directo contra la fisionomía heredada en el barrio. Una coincidencia que no es vivida por los inversores de manera contradictoria y que, por el contrario, a menudo se torna explícita, como se observa en el bautizo de las tres torres-country con los muy castizos nombres de Carlos Gardel, Enrique Santos Discépolo y Aníbal Troilo.

De este modo, el proyecto de rehabilitación y protección del patrimonio histórico y cultural del Abasto va operar como herramienta legitimadora de una intervención diferencial en el barrio. Tal y como apuntan García y Sequera ${ }^{41}$, la "cultura" ejerce como un elemento de consenso que habilita la transformación urbanística, que es presentada a su vez como un ejercicio de "recuperación" del barrio, necesario e intrínsecamente positivo para sus vecinos. Sin embargo, su implementación práctica exige todo un proceso de reordenación física y simbólica, que pronto se traduce en la presión expulsora sobre los sectores populares y en la estigmatización de colectivos específicos, entre los que destacan los ocupantes ilegales de vivienda y

38 Carman, 2006

39 Díaz, 2015.

40 Bauer, 2010.

41 García y Sequera, 2013 
los inmigrantes. Dos colectivos que, tal y como señala la propia María Carman ${ }^{42}$, son identificados sistemáticamente como un idéntico sector de la población.

En efecto, el proyecto de higienización del barrio se plasma en formas específicas de violencia que afectan muy especialmente a la población inmigrante del barrio. Los peruanos, que se habían instalado mayoritariamente en conventillos ubicados en las inmediaciones del centro comercial ${ }^{43}$, sufren con especial intensidad el alcance de un proceso gentrificador cuyo epicentro es el propio Shopping. Pero más allá de esta cercanía material al problema, los propios peruanos van a ser objeto de una construcción discursiva directamente impulsada por los beneficiarios del nuevo proyecto barrial, y que les presenta como un obstáculo al progreso y a la mejora de la zona. Los peruanos, sus casas, sus numerosos comercios y restaurantes, sus ropas y sus formas de habitar el barrio van a ser identificados como un peligro, y en todo caso como un problema.

\section{Los vecinos de Zelaya y su relación con el Abasto}

Cuando los vecinos de la calle Zelaya resultaron afectados por el incendio, en medio del duro invierno de Buenos Aires, tuvieron que improvisar un campamento frente al propio edificio que abandonaban, ahora custodiado permanentemente por policías que impedían el reingreso al mismo. Muchas de las familias habían perdido todo, y atravesaban unos momentos de serias dificultades materiales y fuerte tensión emocional. En este contexto, el campamento se convirtió en un espacio de refugio donde, a pesar de las condiciones adversas, los vecinos resistían a través de la prestación sistemática de ayuda mutua. La comunidad de vecinos se convirtió en una "gran familia" que cooperaba para garantizar el cuidado de todos sus miembros. Pronto se estableció una cocina colectiva, y todos se organizaron para distribuir la ayuda que comenzaban a recibir, en forma de alimentos fundamentalmente, de parte del gobierno de la ciudad, así como de algunas asociaciones y vecinos a título particular.

Estas formas organizativas fueron facilitadas por toda una experiencia previa de relaciones comunitarias que habían sido exigidas por las propias condiciones de inserción en el barrio. La casa que habitaron hasta entonces, vieja y mal conservada, había precisado de intervenciones periódicas que los vecinos habían cubierto de manera solidaria.

\footnotetext{
Nosotros la hemos ido arreglando [la casa]. Todos los chicos ponían la mano. Todos los esposos, o los primos, los hermanos ponían la mano. Hasta las mujeres. Si teníamos que hacer limpieza general, todas las mujeres en el techo. Los hombres bajaban escombros, limpiábamos, limpiábamos los tanques. [tras el incendio, durante la acampada] Claro, entre todos nos turnamos por ejemplo traen comida del gobierno, y algunos queremos tomar una sopa caliente, hacemos un desayuno entre todos. Entre todos nos damos la mano. Hicimos una actividad para cualquier tipo de emergencia, no sé, el gas, comprar una leche, dándose la mano entre todos. (Violeta, 43 años, peruana)
}

42 2005, p. 66

43 Lapenda, 2009, p. 73 
El campamento se convirtió en un espacio de convivencia en el que también se daba un debate permanente sobre la situación que sufrían, incluyendo las causas de su problema, las soluciones que necesitaban y los actores institucionales que debían involucrarse para ayudarles. Todos tenían claro que el trasfondo del incendio era el corte de luz de varios que había provocado Edesur, empresa argentina de distribución eléctrica responsable de la zona. Un corte especialmente doloroso por coincidir en el tiempo con los llamados "tarifazos": fuertes subidas del precio de la luz y otros servicios básicos decretados en los meses anteriores por las grandes empresas del sector y permitidos por el gobierno.

Todos, creo que todos, inmigrantes, y también los mismos argentinos están en este tiempo peor. Con los tarifazos, todos los días alzan las cosas, todos los días: los productos para comer, la carne, el pollo, se subió 400\% más. Este último gobierno se lanzó pero horrible. Nos hizo más pobres de lo que éramos. (Ángela, 37 años, peruana)

En este sentido, la pérdida de la casa tendía a ser enmarcada por los vecinos en un discurso más amplio de pérdida general de derechos y calidad de vida, que todos identificaban con la llegada al poder de Mauricio Macri. Por contraste con el gobierno de Cristina Kirchner, donde sí habían percibido una mejora efectiva en sus vidas, la situación política actual les parecía un retroceso.

Es que nosotros habíamos avanzado mucho con el anterior gobierno. Habíamos conseguido muchas cosas y estábamos muy bien. Pero es que en este país siempre es así: cada diez años llega un gil y se carga todo lo que la gente ha conseguido con la lucha. (Pamela, 33 años, argentina).

La destrucción de la vivienda por el fuego, unida a la falta de alternativas habitacionales en la zona, coloca a estos vecinos ante el riesgo inminente de tener que abandonar el barrio. Esto representa un problema grave para todos ellos, que en sus discursos otorgan un alto valor al lugar en el que viven. Las principales ventajas que perciben de este lugar están relacionadas con su emplazamiento. El hecho de vivir en un barrio central les reporta una conexión fácil con la red de transporte público $\mathrm{y}$, por ende, con los mercados de trabajo en que se insertan. ${ }^{44}$ Igualmente valoran en alto grado los servicios públicos de la zona, fundamentalmente los centros escolares, que consideran mejores que los existentes en la periferia.

No, es que para nosotros es muy importante estar acá. Porque mire que los chicos van todos a las escuelas de acá. Una está ahí a unas cuadras y la otra acá detrás. Y esas de primaria, la de secundaria está para el otro lado pero está cerca igual. Entonces ellos andan siempre moviéndose acá. Y la mayoría de los adultos igual trabajamos por acá. Entonces si nos vamos a provincia ¿dónde trabajamos? (Marco, 39 años, peruano)

Las posibilidades de trabajar no sólo aumentan en el Abasto por su ubicación física. La alta presencia de peruanos en el barrio facilita el acceso al mercado de trabajo. La comunidad de connacionales no sólo ayuda prestando información sobre oportunidades laborales. Además, y al haber abierto en la zona un gran número de

44 Borja, 2013, p. 23 
restaurantes peruanos y otros negocios similares, la propia comunidad ofrece oportunidades de trabajo a los suyos. De hecho muchas de las residentes en el edificio de Zelaya, que son mayoritariamente mujeres y cabezas de familia, se emplean como cocineras o limpiadoras en estos negocios, mientras que otras lo hacen en el servicio doméstico y los hombres, casi todos, en la construcción.

El Abasto también ofrece un ambiente tranquilo y relativamente seguro, por contraste con la principal alternativa habitacional que estas familias pueden permitirse, y que es residir en una villa. Las villas miseria, o villas de emergencia, constituyen asentamientos informales donde, si bien el precio del alquiler es más asequible, los habitantes se exponen a un entorno que es caracterizado como corrupto y peligroso.

Lo que más me gusta del barrio es que tengo todo accesible: para comprar, para los chicos... tengo la placita, puedo tomarme un mate con mis hijos, conversar... es lo que más me agrada del barrio, que es tranquilo. (...) Y no me gustaría ir a la villa, porque no es vida para un chico. No es porque los margine, pero yo no estaría tranquila salir a buscar trabajo y dejarlos allá a los chicos. Porque tú sabes que en una villa, o en cualquier asentamiento que haiga, siempre rigen o las peleas o los balazos. O saber si tú vas a volver en la madrugada bien de tu trabajo y encontrar bien a tus hijos. Acá los chicos pueden salir, jugar, los miramos, los llevamos al parque. (Violeta, 43 años, peruana)

Frente a la villa, que representa el peligro y la exclusión, el Abasto aparece en el discurso como un lugar tranquilo y propicio a la convivencia vecinal ${ }^{45}$. Sin embargo, y a la hora de escapar al peligro de la villa, los barrios centrales presentan como problema estructural una tendencia al alza en el precio del suelo que, en casos como el del Abasto, llega a ser prohibitivo. Es interesante notar en este punto que, en el discurso de estas personas sobre la dificultad de acceder a una vivienda digna en este barrio, existe una alta conciencia sobre el problema de la gentrificación, caracterizada como un ejercicio de violencia que golpea a los sectores más débiles del barrio y que termina expulsándoles hacia zonas periféricas.

Y las inmobiliarias, que se están apropiando de todas las casas antiguas. Está creciendo la... ¿cómo se dice? La especulación inmobiliaria. Y están desapareciendo las casas antiguas y todo esto se está llenando de edificios. Y están echando a la gente que vive tantos años en esa casa. (...) En la ciudad pasa eso: que la gente rica se está apropiando de todo en la ciudad. Y destruyen a la gente de menos recursos. "Que se vayan a provincia". Si no pueden pagar un alquiler, entonces que se vayan a provincia. ¡El país es grande! (ríe). (Ángela, 37 años, peruana)

La presión especulativa sobre el barrio aparece como el trasfondo que dificulta cotidianamente su permanencia en el mismo y, por tanto, como la causa última de sus problemas. Tienen claro que la violencia desatada por este proceso opera fundamentalmente en base a un criterio de clase. Los perjudicados son los secto-

45 Es interesante notar la fuerte carga simbólica que adopta aquí la expresión "tomarme un mate con mis hijos", que subraya al mismo tiempo tres elementos altamente valorizados por la entrevistada: la seguridad del barrio -los niños pueden estar en la calle-, la integración de Violeta en la sociedad argentina -tomar mate sería una señal de aculturación- y la importancia de su rol materno - pasa el tiempo con sus hijos-. 
res populares en su conjunto, y generalmente los vecinos peruanos del barrio no suelen identificar su nacionalidad de origen como una categoría explicativa en este sentido. Sin embargo, cuando se desciende hasta los efectos concretos que sufren las familias, sí mencionan algunas dificultades añadidas por el hecho de ser inmigrantes. Destacan fundamentalmente dos. En primer lugar, el acceso a un alquiler se ve dificultado a veces por la dificultad de contar con una persona "bien considerada" -argentino, se entiende- que ejerza como garante.

La situación en la Argentina, como usted lo habrá visto: no solamente los peruanos. Todo inmigrante tiene el mismo problema: que no puede acceder a vivir como la gente. Que no pueden acceder a ir a alquilar algo, para que pagues. No puedes, porque tú sin un garante, de un condominio o de una casa, no sos nadie. (Violeta, 43 años, peruana)

Por otra parte, las personas peruanas entrevistadas identifican un segundo problema que, si bien de manera indirecta, también afecta negativamente a sus opciones de encontrar vivienda en un barrio como el Abasto. Básicamente interpretan que, en la medida en que se les criminaliza como "invasores" en este barrio, hay algunos residentes que se resisten a aceptarles como vecinos.

Hay una vecina del frente que no nos quiere, nunca nos quiso. Ponía grasa, ¿viste la grasa marcada en los bancos? Para que nadie se siente. Cogía a los chicos, decía: peruanos ¿por qué no se largan a su país? (...) nunca nos ha querido. Peleaba con los chicos... pero nosotros la dejábamos que hable. La vecina de allá, la vecina Rosita nos decía: déjala, pobre, esa mujer está amargada. Pero con el resto de vecinos, muy bien, nunca hemos tenido problemas. (Violeta, 43 años, peruana)

Las actitudes de rechazo xenófobo explícito son citadas siempre como excepciones, y para subrayar por contraste que en términos generales la relación con los vecinos es buena. Es posible que esta percepción esté condicionada por un contexto de desalojo en el que pronto varias organizaciones y vecinos argentinos se interesan por la situación de las familias afectadas por el incendio y se involucran en buscar una solución. En todo caso, se trata éste de un proceso complejo que no está exento de contradicciones.

\section{Confluencias y tensiones en la resistencia a la gentrificación}

A raíz de la instalación del campamento, muchos vecinos de la zona acuden para ofrecer ayuda a las familias afectadas por el incendio, generalmente con comida, ropa y mantas. Adicionalmente, varias organizaciones van a acercarse al campamento para ofrecer un apoyo más estable y sistemático. Nos referimos a asociaciones que luchan por el derecho a la vivienda -CIBA, principalmente-, grupos políticos de izquierdas -Nuevo Encuentro, Patria Grande y La Brecha- y una asociación de inmigrantes integrada mayoritariamente por mujeres peruanas -AMUMRA-. Si bien esta última organización tendrá una presencia más intermitente y distante, los representantes de los tres primeros llegarán a involucrarse de un modo muy intenso, y harán un esfuerzo permanente por dotar a la lucha de los vecinos de un perfil 
expresamente político y conectarla con una agenda más amplia de denuncia de la gentrificación en el barrio.

Estos activistas organizan junto a los vecinos una primera asamblea para tratar el problema, que tiene lugar el mismo día en que se levanta el campamento. Desde entonces, y durante las semanas siguientes, las asambleas se celebran diariamente, a última hora de la tarde. A veces tienen lugar en la calle y otras veces, cuando hace más frío y el espacio está disponible, en un local que pertenece a Nuevo Encuentro y que se encuentra en la misma calle, a escasos veinte metros del campamento.

En las asambleas el ambiente es bueno y prima el compañerismo. En ellas las organizaciones políticas y el CIBA informan de los recursos disponibles para la lucha y muchos de los vecinos intervienen aportando opiniones. Son las organizaciones quienes llevan la iniciativa, y son sus representantes quienes concentran la atención y marcan el ritmo de los debates. No obstante, dichos representantes enfatizan constantemente la necesidad de que los afectados asuman el protagonismo, y trabajan permanentemente para fomentar su participación e involucrarles en responsabilidades concretas. Pronto se va destacando un pequeño grupo de tres o cuatro vecinos peruanos que demuestran ser más activos y que asumen el grueso de las responsabilidades. Entre ellos se encuentra Alba, de treinta y pocos años. Vive con su marido y sus dos hijos, y trabaja en un servicio de madres cuidadoras enmarcado en el Frente de Organizaciones en Lucha (FOL), un conglomerado de movimientos sociales críticos altamente organizado, que además de impulsar movilizaciones políticas sostiene de manera estable un trabajo sólido en los barrios, incluyendo talleres formativos, bachilleratos populares y comedores, entre otros. Es interesante que la propia Alba llegó al Abasto huyendo de una villa donde su activismo le había colocado en la diana de narcotraficantes.

Ya te conocen que eres luchadora, la gente mala como que te mira y te ve como un obstáculo, viste. Un obstáculo. O sea que los jóvenes de ahí, en vez que se dediquen a la droga o a vender, los movimientos los jalan para que los jóvenes trabajen, se organicen, trabajen en cualquier cosa, viste: construcción, panadería... Y la gente mala ve a ellos como sus enemigos, que le están jalando su gente. Y por eso es que más o menos tuvimos problemas. (Ángela, 37 años, peruana)

Alba, en este sentido, atesora una experiencia militante que le habilita para manejar los códigos de las organizaciones políticas argentinas, incluyendo su vocabulario, sus referentes y sus ritmos. Pronto asume, junto a Felipe -otro peruano de unos cuarenta años que vive en el campamento junto a su mujer e hijos- una función mediadora. En las asambleas, sus intervenciones suelen tener como objetivo amplificar el discurso de las organizaciones para convencer a los vecinos de la necesidad de "politizar" la lucha -movilizarse, participar activamente, etc.- y, en sentido inverso, negociar los ritmos con las organizaciones políticas y hacerles entender los códigos de los vecinos.

Estas tareas apuntan a los conflictos que van a atravesar toda la relación de los vecinos con las organizaciones argentinas que les apoyan. Más allá del respeto 
personal, y del cariño que en seguida va fraguando en las relaciones cotidianas, las relaciones van a estar marcadas por una tensión permanente derivada del manejo de códigos y ritmos diferentes. Básicamente, los vecinos temen que una politización del problema en términos partidistas pueda afectar negativamente a sus intereses. Algunos de ellos sólo quieren volver a entrar a la casa para arreglarla, o recibir a cambio alojamiento en un lugar cercano, y creen que visibilizarse junto a opositores de izquierda y kirchneristas puede dificultar sus relaciones con el gobierno de derechas de la ciudad. Los activistas, por su parte, están convencidos de que es necesario desarrollar un programa de lucha sostenido en el tiempo, e involucran a los vecinos en actividades como reparto de octavillas, concentraciones y hasta una ocupación de la avenida Corrientes - una de las principales de Buenos Aires- con corte de tráfico durante una hora. Si bien la respuesta de los vecinos a estas propuestas es positiva, los activistas no encuentran siempre el entusiasmo y la disciplina que esperan. Pronto se va generando entre ellos la idea de que estas familias son desordenadas y sufren un problema severo de falta de conciencia política.

Esta actitud crítica hacia los vecinos no suele adoptar una forma agresiva, pero sí va impregnando los discursos de un tono paternalista, que enfatiza permanentemente la necesidad de "establecer prioridades". Para los activistas, el problema de estas familias peruanas es que pierden tiempo en actividades que no contribuyen a solucionar su situación, y son lentos y dubitativos a la hora de afrontar las tareas centrales de la lucha política. Esta opinión se pone de manifiesto expresamente durante la asamblea del 28 de julio, celebrada en el local de Nuevo Encuentro. A las puertas del local, y sobre una mesa forrada por banderas peruanas, un grupo de vecinas prepara comida de su país para celebrar tras la asamblea las Fiestas Patrias, en conmemoración de la declaración de independencia del Perú por José San Martín. Algunos vecinos entran y salen de la asamblea, alternando su participación en la misma con la prestación de ayuda en los preparativos de la comida. Esto incomoda visiblemente a los activistas argentinos, que lamentan que los vecinos no se concentren en la asamblea y que llegan a quejarse expresamente de lo que interpretan como una falta de seriedad en la lucha. La tensión alcanza un grado máximo cuando un grupo de mariachis interrumpe la asamblea. Son mexicanos afincados en Buenos Aires, amigos de algunos de los vecinos peruanos y vienen a celebrar las Fiestas Patrias. Los vecinos, muy contentos, disfrutan durante más de media hora de rancheras y corridos, tocan las palmas y acompañan los coros. Los activistas argentinos, notablemente molestos, esperan con cara seria y mirándose entre ellos. A una dirigente de La Brecha le cuesta contenerse el enfado por la interrupción de la asamblea, y durante la interpretación de "Sigo siendo el Rey", de Vicente Fernández, alza la voz para que se escuche, por encima del "llorar y llorar" que corean los asistentes, un "luchar y luchar" que condensa su contrariedad.

Lo interesante en este punto es que los peruanos más involucrados en la lucha no parecen sufrir esa contradicción. Alba, Felipe y el resto de los dirigentes vecinales ríen y cantan junto a los demás. Para entender esta percepción diferente es preci- 
so considerar el sentido que ellos dan a la celebración de estas Fiestas Patrias. En este sentido, se hace patente en las siguientes declaraciones que la celebración de estas fiestas forma parte de un conjunto más amplio de formas de comunitarismo que consideran crucial para reforzar la cohesión de los vecinos en tanto peruanos y mantener así la unidad del grupo.

Cuando había el Día de la Madre Peruana (sic), hacíamos un compartido entre todas. O sea, cocinábamos entre todas y comíamos. Festejábamos el día de la Madre, el Día del Niño, para Navidad, entre vecinos: era como una familia. (...) También se celebran las fiestas peruanas. Por ejemplo el 28 de julio cuando hubo de acá, viste, que vinieron gente peruana para el 28 de julio. Acá nosotros también nos vamos a algún lugar donde celebran las Fiestas Patrias, o hacíamos una comida peruana, comíamos con los chicos... Eran, a pesar de que eran discusiones también eran alegrías. (Violeta, 43 años, peruana)

Lejos de responder a una falta de conciencia política, el recurso a ciertas tradiciones festivas peruanas parece conectar con una necesidad estratégica de crear comunidad, que está muy presente entre los vecinos y que demuestra tener importantes aplicaciones prácticas. Un caso evidente es el de la pollada, una iniciativa que los vecinos desarrollan periódicamente. La pollada consiste en cocinar colectivamente pollo "al estilo peruano" para invitar a los connacionales, que a cambio hacen una aportación económica a los organizadores. Esta práctica nunca fue reconocida por los activistas argentinos como una iniciativa política, y siempre fue vista como una actividad recreativa orientada al disfrute. Sin embargo, la pollada no es sólo una excusa para comer con los amigos, sino que forma parte de una estrategia más amplia de construcción de redes de solidaridad y recaudación de fondos para la lucha.

Para organizarnos hacemos una pollada entre los vecinos, y recaudamos dinero con eso. Porque esa comida solamente la hacemos para hacer una actividad, y para recaudar fondos. Pro-salud, pro-casa, pro-esto o pro-cualquier cosa pero es apoyar, es una comida especial. (...) Si había que arreglar la casa, todos juntos. Esa reja, por ejemplo, la pusimos todos juntos, la reja de la puerta. Recaudábamos cada vecino, cuánto toca, entre todos poníamos. (Ángela, 37 años, peruana)

Los activistas argentinos no eran incapaces de entender la utilidad práctica de las polladas y otras iniciativas de los vecinos. Pero sí consideraban que esas actividades debían ocupar un papel secundario respecto a "la lucha". Una lucha que, por definición, sólo podían concebir en el marco de los códigos propios de la militancia tradicional de izquierdas: concentraciones, manifestaciones, protestas, etc. Sin embargo, para los peruanos las necesidades derivadas del incendio hacían aún más importante el recurso a actividades como la pollada, comida colectivas o fiestas de cumpleaños. Su experiencia vecinal en el Abasto contiene una alta dosis de comunitarismo entre connacionales, y el sentimiento comunitario se hace especialmente necesario en las duras condiciones del desalojo. Dar continuidad a estas formas de apoyo mutuo no era percibido como una pérdida de tiempo, sino como un recurso básico para reforzar la unidad y la solidaridad del grupo. 
Las relaciones entre los activistas argentinos y los vecinos peruanos nunca llegaron a romperse definitivamente, pero fueron enfriándose hasta limitarse a contactos puntuales. En gran medida esto sucedió por una distancia importante en los códigos que unos y otros usaban en el desarrollo cotidiano de la lucha por el derecho a vivir dignamente en el barrio. Aquello que los activistas interpretaban como prácticas de ocio que distraían de lo importante y ralentizaban la lucha, eran para los vecinos iniciativas cruciales para reforzar los lazos comunitarios y fomentar la cohesión interna del grupo. Esta tensión fue vivida con especial intensidad entre los vecinos peruanos que asumieron el liderazgo. Por tener algunos cierta trayectoria militante y conocer los códigos de las organizaciones argentinas que les apoyaban, tuvieron que asumir un difícil papel como intérpretes entre unos y otros.

\section{Conclusiones}

A lo largo de los últimos veinte años, el Abasto ha experimentado un conjunto de transformaciones urbanísticas que se ajustan de manera arquetípica al modelo de gentrificación observado en numerosas ciudades de todo el mundo. El estado de degradación que este barrio presenta a fines de los noventa, así como la potencialidad de su localización central y su condición de barrio histórico -especialmente por su vinculación a los orígenes del tango-, opera como un reclamo para grandes inversores, que impulsan una ambiciosa operación financiera con el objetivo de extraer beneficios mediante la revalorización del precio del suelo. Esta intervención entraña necesariamente la puesta en juego de recursos discursivos que movilizan una concepción patrimonialista del barrio, y que preconizan la recuperación de una identidad cultural en peligro. La reivindicación de referentes simbólicamente asociados al Abasto, como el tango y la figura de Carlos Gardel, contribuye a reforzar un discurso que legitima la acción gentrificadora como una empresa necesaria y de interés general.

Este proceso genera colateralmente la visibilización de colectivos que pasan a ser construidos como extraños al barrio, pese a ser vecinos del mismo, y como usurpadores del territorio. En este contexto, los peruanos van a ser identificados como una amenaza especialmente perturbadora, por cuanto son presentados como triplemente usurpadores: usurpadores de la propiedad inmobiliaria, del patrimonio argentino y del territorio nacional. Esta construcción del inmigrante peruano llega a tener una fuerte presencia en los medios de comunicación, y es asumida en ciertos discursos reproducidos por representantes políticos y por parte del vecindario. Al estigmatizar a esta población, este discurso cuestiona su derecho a residir en el barrio y justifica consecuentemente las transformaciones urbanísticas en curso.

El caso analizado nos ofrece datos interesantes para el contraste de las estrategias de resistencia a la expulsión por parte de los vecinos peruanos. En este sentido, las veintisiete familias residentes en el edificio incendiado de la calle Zelaya parecen conjugar dos principios básicos. En primer lugar, se observa un refuerzo de formas organizadas de reciprocidad vecinal para hacer frente a las dificultades materiales 
cotidianas y que se construyen en torno a la identidad peruana. Así, la práctica sistemática del apoyo entre connacionales se constata a lo largo de toda su experiencia en el Abasto, incluyendo la gestión colectiva del cuidado de los hijos, el pago solidario de los servicios básicos y la organización de actividades coordinadas para sufragar gastos extraordinarios y realizar tareas de mantenimiento del inmueble. Paralelamente, los peruanos practican una intensa sociabilidad barrial que les lleva a relacionarse con vecinos argentinos y de otras nacionalidades, y valoran en alto grado el sentimiento de estar integrados en el barrio.

Esa participación normalizada del barrio les permite recabar diversas formas de apoyo vecinal tras el desalojo de la casa. Especialmente intensa será la relación que entablen con un grupo de vecinos argentinos altamente politizados y que se involucran en tanto miembros de organizaciones críticas con la gentrificación del barrio. La experiencia de la acampada, y el desarrollo de múltiples iniciativas para denunciar la situación de los desalojados y exigir una solución, pone de manifiesto un caso notable de convergencia entre peruanos y argentinos en la lucha por un modelo de ciudad más justo y solidario. Sin embargo, esta experiencia también va a evidenciar tensiones importantes entre culturas organizativas muy diferentes. Mientras que los militantes argentinos apuestan por formas de movilización ajustadas a la tradición de la izquierda y construidas sobre referentes de clase, los vecinos peruanos refuerzan actividades que priorizan la sociabilidad entre connacionales, generalmente construidas sobre la identidad peruana compartida y a menudo en un formato festivo e informal. Esta tendencia es identificada por los militantes argentinos como un obstáculo al éxito de la lucha, que es explicada por una falta de conciencia política. Para los vecinos, sin embargo, el sostenimiento de estas prácticas tras el incendio es clave para reproducir la misma lógica de reciprocidad que siempre fue crucial para mitigar la precariedad estructural que sufren y posibilitar su vida en el barrio.

La lucha contra la gentrificación, en definitiva, abre un espacio en el Abasto para la convergencia entre inmigrantes y autóctonos en pos de un objetivo común. Pero esta experiencia se ve atravesada por tensiones que entroncan con la situación desigual de las partes. Mientras que los militantes argentinos apuestan por movilizaciones organizadas en clave vecinal y de clase, los peruanos necesitan combinar estas iniciativas con el refuerzo de una identidad nacional que es crucial para sostener los mecanismos solidarios que contrarrestan su mayor vulnerabilidad y, por tanto, su mayor exposición al problema. Si la iniciativa gentrificadora moviliza discursos sobre la identidad argentina para justificar la transformación del barrio, el refuerzo de la identidad peruana resulta clave entre los inmigrantes para resistir su especial exposición a los efectos más duros de la gentrificación. 


\section{Bibliografía}

ARENALES LOPE, Alba. Identidad, espacio y formas de acción: Un análisis del movimiento de Gamonal, Burgos. In ARICÓ, Giuseppe; MANSILLA, José A. y STANCHIERI, Marco Luca. Barrios corsarios. Memoria histórica, luchas urbanas y cambio social en los márgenes de la ciudad neoliberal. Barcelona: Pol-len edicions, 2016, p. 117-134.

ARICÓ, Giuseppe; MANSILLA, José A. y STANCHIERI, Marco Luca. Desentrañando la periferia urbana. Espacio, tiempo y rasgos de los espacios corsarios. In ARICÓ, Giuseppe; MANSILLA, José A. y STANCHIERI, Marco Luca. Barrios corsarios. Memoria histórica, luchas urbanas y cambio social en los márgenes de la ciudad neoliberal. Barcelona: Pol-len edicions, 2016, p. 17-36.

BAUER, Luis. Transformaciones urbanas y de la estructura social de un barrio de la ciudad de Buenos Aires. Economía, Sociedad y Territorio, 2010, X(33), p. 283-325.

BORJA, Jordi. El fin de la ciudad postmodernista y el derecho a la ciudad o claves para interpretar la ciudad postmodernista urbanicida. In RESTREPO, Gustavo; BERNAL, Felipe; BRAU, Lluís; GRAU, Sebastián; PEMÁN, Ignacio; EIBENSCHUTZ, Roberto y MOLINA, Pablo. Memorias del XV Congreso Iberoamericano de Urbanismo. Medellín: Editorial Universidad Pontificia Bolivariana, 2013, p. 1633. <aetu.es/app/download/5791915220/MEMORIAS+XV+CIU+CON+ISSN.pdf> [Consulta: 28 de septiembre de 2017]

CANEVARO, Santiago. Migración, crisis y permanencia de la migración peruana en Buenos Aires. Trayectorias laborales e identidades sociales de mujeres en el servicio doméstico. IX Congreso Argentino de Antropología Social. Posadas: Facultad de Humanidades y Ciencias Sociales - Universidad Nacional de Misiones, 2008, p. 1-26. <http://cdsa.aacademica.org/000-080/384> [Consulta: 28 de septiembre de 2017]

CAPEL, Horacio. Los inmigrantes en la ciudad. Crecimiento económico, innovación y conflicto social. Scripta Nova. Revista Electrónica de Geografía y Ciencias Sociales, 1997, núm. 3. <http://www.ub.edu/geocrit/sn-3.htm> [Consulta: 28 de septiembre de 2017]

CARMAN, María. Las trampas de la cultura. Los intrusos y los nuevos usos del barrio de Gardel. Buenos Aires: Paidos, 2006, 272 p.

CARMAN, María. El barrio del Abasto, o la invención de un lugar noble. Runa, 2005, XXV, p. 79-96. <http://www.redalyc.org/pdf/1808/180820990004.pdf> [Consulta: 28 de septiembre de 2017]

CASGRAIN, Antoine y JANOSCHKA, Michael. Gentrificación y resistencia en las ciudades latinoamericanas. El ejemplo de Santiago de Chile. Andamios. Revista de Investigación Social, 2013, 10 (22), p. 19-44. <http://www.redalyc.org/ pdf/628/62828837002.pdf> [Consulta: 28 de septiembre de 2017]

CASTELLS, Manuel. El poder de la identidad. La Era de la Información, Vol. 2. Madrid: Alianza Editorial, 2003, 568 p. 
CERRUTTI, Marcela. Derechos Sociales, Mercado de Trabajo y Migración Internacional en Argentina. "Issues paper" elaborado para el Informe Nacional sobre Desarrollo Humano 2013 del PNUD Argentina, 2012.

CERRUTTI, Marcela. La migración peruana a la Ciudad de Buenos Aires: su evolución y características. Población de Buenos Aires, 2005, 2(2), p. 7-28. <http://www. redalyc.org/pdf/740/74020201.pdf> [Consulta: 28 de septiembre de 2017]

CLARK, Erick. The order and simplicity of gentrification: a political challenge. In ATKINSON, Rowland y BRIDGES, Gary. Gentrification in a global context. The new urban colonialism. London: Routledge, 2005, p. 261-269.

DALMAU I TORVÀ, Marc. La pulverización de una colonia obrera: un barrio bajo atrapado en una zona alta. In ARICÓ, Giuseppe; MANSILLA, José A. Y STANCHIERI, Marco Luca. Barrios corsarios. Memoria histórica, luchas urbanas y cambio social en los márgenes de la ciudad neoliberal. Barcelona: Pol-len edicions, 2016, p. 77-100.

DÍAZ, Ibán. Las manos sobre la ciudad. Carlos Slim y George Soros como agentes de la gentrificación. El canelazo de la ciudad, 2015, 5, p. 66-78.

DIRECCIÓN NACIONAL DE MIGRACIONES. Patria Grande. Programa Nacional de Normalización Documentaria Migratoria. Informe Estadístico, agosto 2010. <http://www.migraciones.gov.ar/pdf_varios/estadisticas/Patria_Grande.pdf> [Consulta: 28 de septiembre de 2017]

ESPINOSA ZEPEDA, Horacio. Neo-higienismo y gentrificación en el discurso de la movilidad urbana: Desalojo de "tiangueros" en Guadalajara, México. In ARICÓ, Giuseppe; MANSILLA, José A. y STANCHIERI, Marco Luca. Barrios corsarios. Memoria histórica, luchas urbanas y cambio social en los márgenes de la ciudad neoliberal. Barcelona: Pol-len edicions, 2016, p. 173-196.

GARCÍA, Eva y SEQUERA, Jorge. Gentrificación en centros urbanos: Aproximación comparada a las dinámicas de Madrid y Buenos Aires. Quid 16, 2013, nº 3, p. 4966.

GLAZER, Nathan and MOYNIHAN, Daniel Patrick. Beyond the Melting Pot: the Negroes, Puerto Ricans, Jews, Italians and Irish of New York City. Cambridge, Massachusetts: MIT Press, 1963, 464 p.

HARVEY, David. Diecisiete contradicciones y el fin del capitalismo. Madrid: Traficantes de sueños, 2014, 294 p.

HARVEY, David. Ciudades rebeldes. Del derecho de la ciudad a la revolución urbana. Madrid: Akal, 2013, 238 p.

HARVEY, David. Urbanismo y desigualdad social. Madrid: Siglo XXI, 1977, 340 p.

HEUSE, Gisela. La "recuperación" del barrio del abasto. Más allá del shopping y del negocio inmobiliario. Revista Kairos, 2004, $\mathrm{n}^{\circ} 11$.

KONG, Lily and YEOH, Brenda S.A. The Politics of Landscapes in Singapore:Constructions of "nation". Syracuse: Syracuse University Press, 2003, 254 p.

LAPENDA, Marina Laura. Migrantes peruanos en la ciuad de Buenos Aires. configuración de espacio de vida y espacios vividos. Tesis de Licenciatura, 2009. 
LEFEBVRE, Henri. La producción del espacio. Madrid: Capitán Swing, 2013, 468 p. MARTÍNEZ VEIGA, Ubaldo. Pobreza, segregación y exclusión social. La vivienda de los inmigrantes extranjeros en España. Barcelona: Icaria, 1999, 176 p.

WEBER, Rachel. Extracting Value from the City: Neoliberalism and Urban Redevelopment. Antipode, 2002, 34 (3), p. 519-540.

WINCHESTER, Hilary; KONG, Lily and DUNN, Kevin. Landscapes: ways of imagining the world. Harlow: Pearson, 2003, 206 p.

(c) Copyright: Francisco José Cuberos Gallardo, 2018

(C) Copyright: Scripta Nova, 2018.

Ficha bibliográfica:

CUBEROS GALLARDO, Francisco José. Relaciones interétnicas yr lucha contra la gentrificación en el barrio de El Abasto, Buenos Aires. Scripta Nova. Revista Electrónica de Geografía y Ciencias Sociales. Barcelona: Universidad de Barcelona, 15 de agosto de 2018, vol. XXII, $\mathrm{n}^{\circ}$ 596. [ISSN: 1138-9788] 